\title{
Study on Rust Characterization and Prediction of Atmospheric Corrosion Rates for Structural Steels in Yangon (Myanmar)
}

\author{
Thinzar Khaing $^{1 *}$, Yu Yu Kyi Win ${ }^{2}$, Nyan Myint Kyaw ${ }^{3}$ \\ Ph.D., Professor, Department of Civil Engineering, Yangon Technological University, Yangon, Myanmar ${ }^{1}$ \\ Ph.D., Sub-Assistance Engineer, Engineering Department, Yangon Region Development Committee, Yangon, \\ Myanmar $^{2}$ \\ Ph.D., Professor and Head, Department of Civil Engineering, Yangon Technological University, Yangon, Myanmar ${ }^{3}$ \\ *Corresponding author: thinzar@ytu.edu.mm
}

\begin{abstract}
According to Fontana, "Corrosion is defined as the deterioration of a material because of reaction with its environment". The present study is performed to get the behaviour of rust characterization and to predict long term atmospheric corrosion rates of structural steels in Yangon, Myanmar. Three types of structural steel (Type A, Type B and Type C) samples which are commonly used in Myanmar are exposed outdoors according to BS EN ISO 8565. They are removed one month periods, and their mass losses are determined according to ISO 8407 in Yangon Technological University. At the same time, environmental parameters of the test site are monitored. Rust characterization of structural steels is determined by Scanning Electron Microscopy (SEM) results in University Research Centre (Yangon University, Myanmar). From SEM results, Type A and Type B steels have nearly the same image controlled by $\beta$-FeOOH which can increase long term corrosion, whereas Type $\mathrm{C}$ steel has controlled by $\gamma$-FeOOH. A prediction model is developed using SPSS software to understand the main factors which cause the atmospheric corrosion, and it is found that the atmospheric corrosion in Yangon depends mainly on the time of wetness (TOW). From prediction of atmospheric corrosion by using Linear Bilogarithmic equation, Type $\mathrm{C}$ steel is the best.
\end{abstract}

Keywords-Atmospheric steel corrosion, Scanning Electron Microscopy (SEM), Structural Steel, time of wetness TOW

\section{INTRODUCTION}

$\mathrm{T}_{\mathrm{b}}$ corrosive environments present a unique challenge to structural engineers in terms of the proper selection of materials and decisions on the sizes of structural members for structure intended to operate over a range of local climatic conditions. This material degradation mechanism comes at a great cost to society.

Like other natural hazards such as earthquakes or severe weather disturbances, corrosion can cause dangerous and expensive damage to everything from pipelines, bridges, and public buildings to vehicles, water and wastewater systems, and even home appliances. Unlike weatherrelated disasters, however, there are time-proven methods known as corrosion management to prevent and control corrosion that can reduce or eliminate its impact on public safety, the economy, and the environment. In general, types of corrosion are general or uniform corrosion, localized corrosion; velocity induced corrosion, and mechanically assisted corrosion. The corrosion that occurs in the atmosphere is known as atmospheric corrosion and it accounts for more failure than other types of corrosion.

Yangon is the country's largest city with a population of about seven million and area of $598.75 \mathrm{~km}^{2}$ and is the most important commercial centre. Yangon has a tropical monsoon climate under the koeppen climate classification system. The city features a lengthy rainy season from May through October, where a substantial amount of rainfall is received; and a dry season from
November through April, where little rainfall is seen. It is primary due to the heavy precipitation received during the rainy season. During the course of the year, average temperatures show little variance, with average highs ranging from 29 to $36^{\circ} \mathrm{C}$ and average lows ranging from 25 to $18^{\circ} \mathrm{C}$.

In Yangon, there is an increasing use of structural steel, especially in the fabrication of structures, such as steel buildings. However, the basis information concerning its resistance to atmospheric corrosion in the Yangon atmosphere is not readily available.

This paper has identified about the nature of corrosion products, paying special attention to the rust characterization based on Scanning Electron Microscopy (SEM) and prediction of atmospheric corrosion for long term.

\section{CORROSION IN MYANMAR}

Myanmar is the north-western-most country on the mainland of Southeast Asia. It is strategically located near major Indian Ocean shipping lanes. It is a developing country and due to the increasing of industry at the main cities, such as Yangon, Mandalay, and so on, the pollution level is also arising. There is an increasing use of structural steel, especially in the fabrication of structures, such as steel buildings.

Figure 1 and 2 shows the deterioration of moving shoe and truss due to corrosion.

It is generally known that steel bridges in the coastal areas are subjected to accelerated paint deterioration by the influence of sea breeze. Steel bridges in Myanmar are 
also subjected to accelerated damage and corrosion in major parts like bolted joint. Figure 3 shows corrosion of Myaungmya Bridge and as shown in Figure 4, in Myaungmya Bridge (suspension bridge) completed in 1996, stands of the main cable are partially broken and corroded. If the breakage of the main cable progresses, a high risk of collapse of bridge will occur.

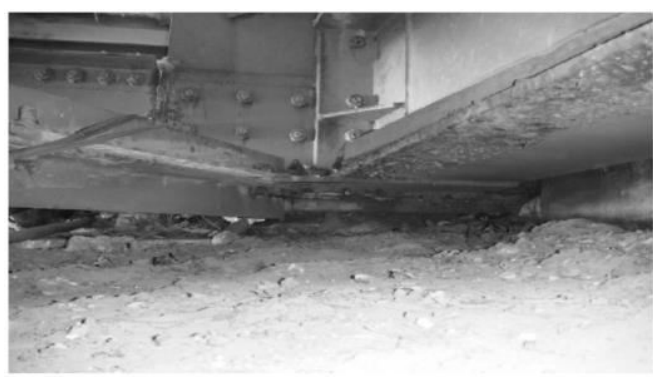

Figure 1. Moving Shoe of Bayinaung Bridge

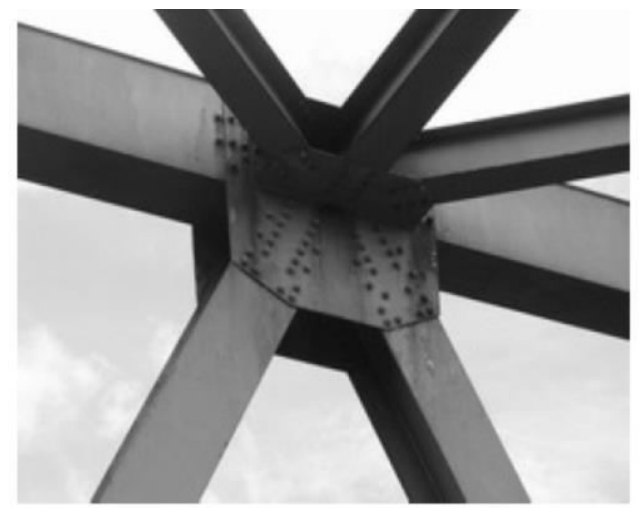

Figure 2. Rust Panel Point of the Truss (Bomyatun Bridge)

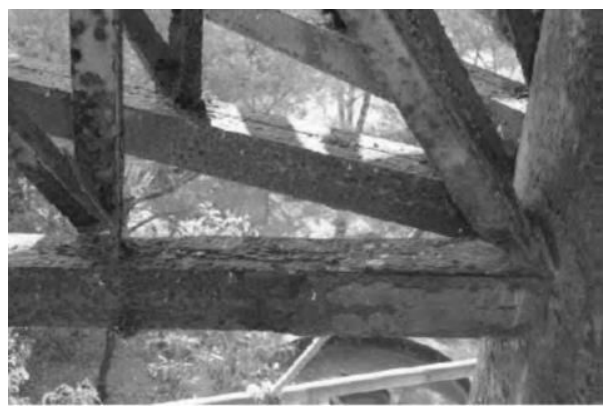

Figure 3. Myaungmya Bridge Corrosion

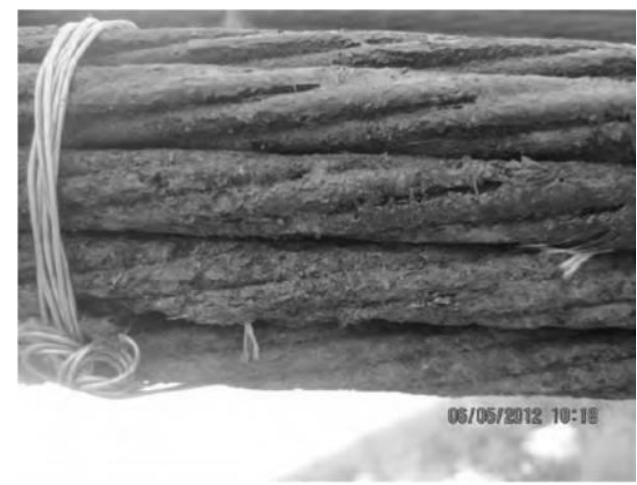

Figure 4. Myaungmya Bridge Main Cable Damage

\section{EXPRIMENT}

To study the atmospheric corrosion of the metals, field tests are very useful than laboratory experiments.

\section{A. Select the Location of Exposure Test}

The severity of atmospheric corrosion tends to vary significantly among different locations, and, historically, it has been customary to classify environments as rural, urban, industrial, marine, or combinations of these.

Yangon is the former capital and economic of Myanmar and has the population of about 7 million and there are many buildings constructed with different construction materials and have suffered severe environmental conditions than ever before. There is an increasing use of structural steel, especially in the fabrication of structures, such as steel buildings. However, the basis information concerning its resistance to atmospheric corrosion in Yangon is not readily available.

Therefore, it becomes the most important problem to study the various durability evaluations for corrosion of construction materials, especially for steel in Yangon. In this research, Yangon (Urban) location is selected as a Study area. The exposure test is done on the roof slab of the main building of Yangon Technological University (YTU) in Yangon.

Table 1 shows the description of the test site and Figure 5 shows the location of test site.

\begin{tabular}{lll} 
& \multicolumn{2}{l}{ Table 1.Location of test site } \\
\hline Environment & Location & Description \\
\hline Urban & Yangon & $\begin{array}{l}\text { Under the third floor ,Yangon } \\
\text { Technological University, Yangon, } \\
\text { Myanmar } \\
\text { (Nearly } 50 \mathrm{ft} \text { height from the } \\
\text { ground) }\end{array}$ \\
\hline
\end{tabular}

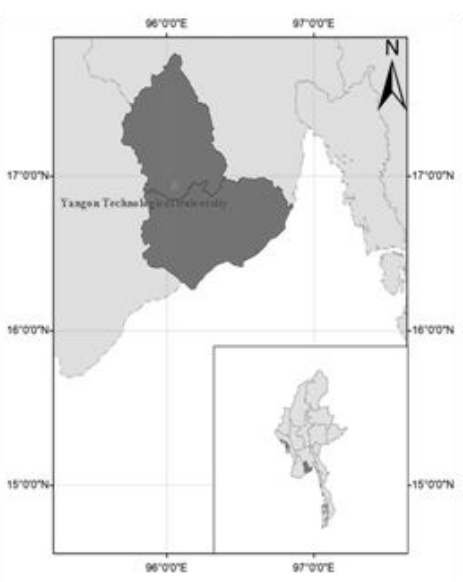

Figure 5. Location of test site

\section{B. Select the Type of Steel Plates}

In this research, three types of steel are studied which are commonly used in Yangon, Myanmar. They are Type A, Type B, and Type C steel that composition is based on Steel grades according to American Standards. Type A steel is A 36 steel and Type B and Type C steels are A 572 and A 242 steels, respectively according to American Standard of Testing Material (ASTM). 
Table 2.Chemical Composition of selected structural steels

\begin{tabular}{|c|c|c|c|c|c|c|c|}
\hline \multirow{2}{*}{ Material } & \multicolumn{7}{|c|}{ Chemical Composition (\% by weight) } \\
\hline & $\mathrm{C}$ & $\mathrm{Si}$ & $\mathrm{Mn}$ & $\mathrm{P}$ & $S$ & $\mathrm{Cu}$ & V \\
\hline Type A & $\begin{array}{l}0.25 \\
\max \end{array}$ & $\begin{array}{c}0.4 \\
\max \end{array}$ & - & $\begin{array}{l}0.04 \\
\max \end{array}$ & $\begin{array}{l}0.05 \\
\max \end{array}$ & - & - \\
\hline Type B & $\begin{array}{l}0.23 \\
\max \end{array}$ & $\begin{array}{c}0.4 \\
\max \end{array}$ & $\begin{array}{l}1.35 \\
\max \end{array}$ & $\begin{array}{l}0.04 \\
\max \end{array}$ & $\begin{array}{l}0.05 \\
\max \end{array}$ & - & $\begin{array}{l}0.01- \\
0.05\end{array}$ \\
\hline Type C & $\begin{array}{l}0.15 \\
\max \end{array}$ & - & $\begin{array}{l}1.00 \\
\max \end{array}$ & $\begin{array}{l}0.15 \\
\max \end{array}$ & $\begin{array}{l}0.05 \\
\max \end{array}$ & $\begin{array}{c}0.2 \\
\max \end{array}$ & - \\
\hline
\end{tabular}

\section{Construct the Exposure Rack for Placing the Specimens}

Exposure rack is constructed according to ISO 8565 with the steel and coated with paint to prevent rusting. Porcelain washer, brass nuts, and bolts are used to fix the test panels at 45 degree with respect to base. At the bottom of the rack, there has concrete block to control the rack. Figure 6 shows the construction of the test rack.

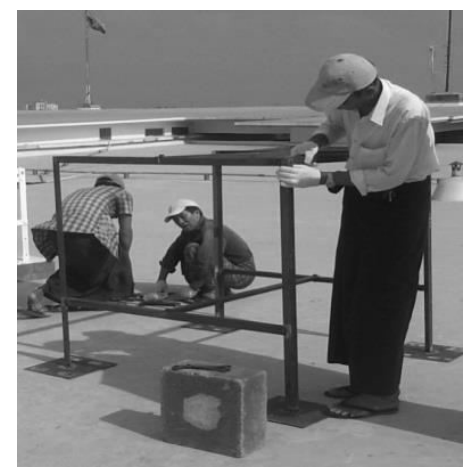

Figure 6. Construction of exposure rack

\section{Specimen Exposure Test}

Panel specimens are typically placed in racks. They are electrically insulated from the racks on which they are mounted and are arranged so that drips from neighboring panels do not contaminate them, as shown in Figure 7. Flat and rectangular specimens are mounted horizontally, facing the same direction as the panels

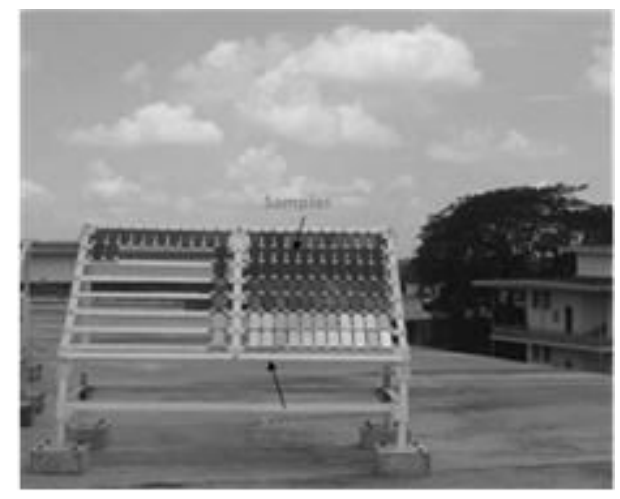

Figure 7. Test rack after placing test specimen

\section{E. Duration of Exposure}

Twenty four specimens of steel for each type of steel were exposed at the same time starting from August, 2014 and after the completion of every month, one plate of each type as removed to get corrosion loss and one was removed for rust characterization. The specimen for corrosion loss was gotten by cleaning and weighting, which gives the progressive weight loss of that particular time interval. Therefore, successive corrosion rates for one, two, three months up to twelve months were got. The specimen for rust characterization was sent to URC (University Research Centre) at Yangon University to test SEM.

\section{F. Calculating of Corrosion Loss}

To determine the mass of specimen due to corrosion, the removal of corrosion products from corrosion test specimens are first done according to ISO 8407. The difference of mass between before and after the removal of corrosion product is called mass loss and the corrosion rate can be calculated by dividing the mass loss by ADT, where, A is initial exposed surface area of coupon, $\mathrm{T}$ is the exposure time, and D is the density of coupon metal. Figure 8 shows removal of corrosion products according to ISO 8407 .
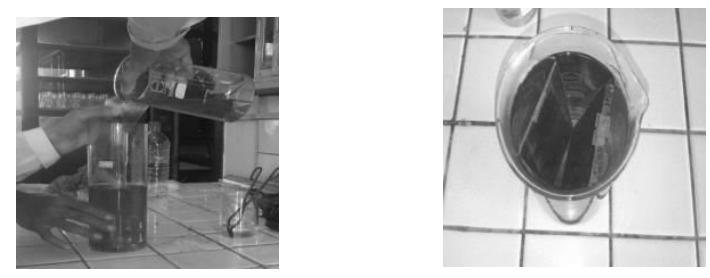

Figure 8. Cleaning of test specimens

\section{G. Collecting Meteorological Data}

The meteorological data collected during this study are solar radiation, temperature, humidity, rainfall, and wind speed. Among these data, the common data affected to corrosion are temperature, humidity, and rainfall. These are collected by CR 1000 data logger shown in Figure 9.

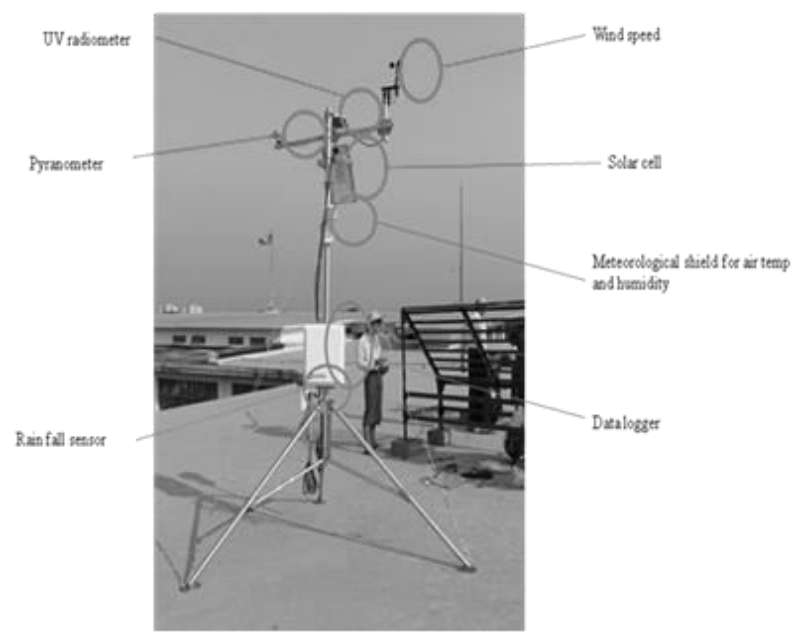

Figure 9. Weather monitoring system

\section{RESULTS AND DISCUSSION}

SEM of tested specimens is tested at University Research Center (URC) and cleaning procedure for corrosion loss is done at Engineering Chemistry Department, Yangon Technological University. 


\section{A. Characterization of the Test Atmosphere}

Figure 10, 11 and 12 show the variations in the temperature, relative humidity, and time of wetness during the study period.

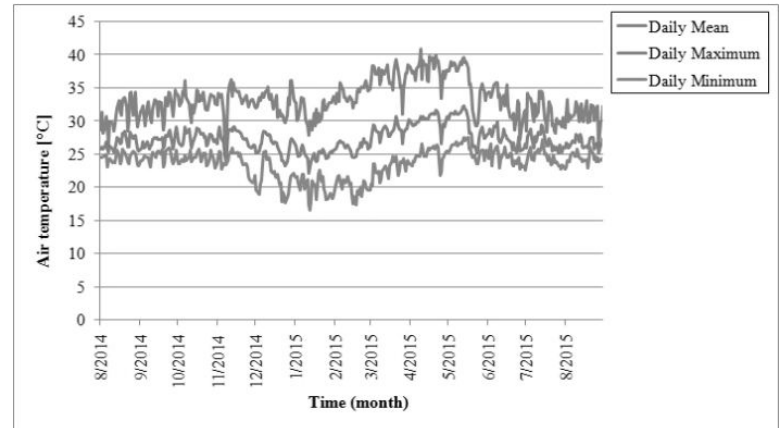

Figure 10. Monthly temperature variation in the environment

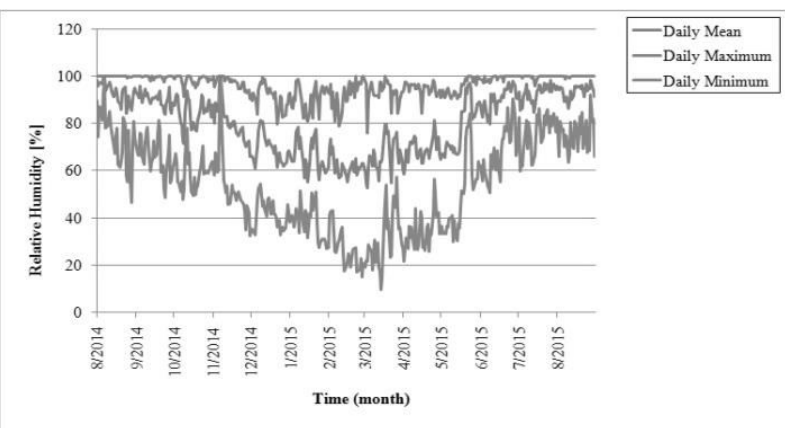

Figure 11. Monthly relative humidity variation in the environment

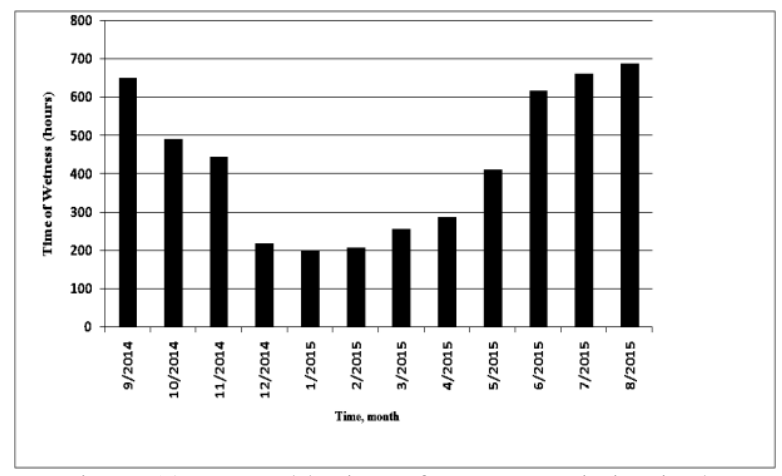

Figure 12. Monthly time of wetness variation in the environment

From June to November, maximum relative humidity can be seen over $90 \%$. The minimum temperature is suffered from December to January and the maximum temperature gets from April to May. According to ISO 9223, TOW is obtained by taking hours in which relative humidity greater than $80 \%$ and temperature greater than $0{ }^{\circ} \mathrm{C}$. From June to November, TOW is greater than 600 hours and in December to February, TOW is nearly equal to 200 hours. According to test results, TOW is directly proportional to relative humidity.

Rainfall is an important factor in the runoff process. Figure 13 shows the amount of rainfall during the studied period, which averaged $192.34 \mathrm{~mm}$ per month. The month of July has the highest rainfall of $571.8 \mathrm{~mm}$ per month. There was no rainfall in December, January, and February.

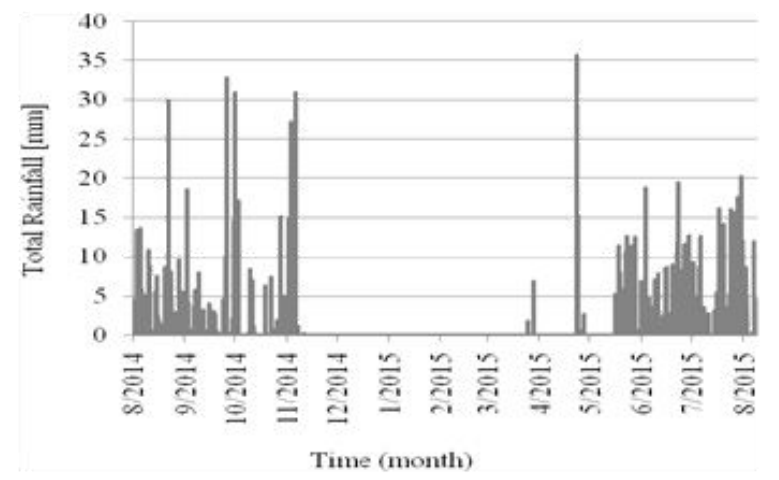

Figure 13. Rainfall variation in the environment

Figure 14 shows the variations in the wind speed. This parameter is important because the speed, origin and direction of the wind influence the amount of pollutants in the air, the chemical composition of the rainwater and the speed of the test plate drying process, which affects the time of wetness.

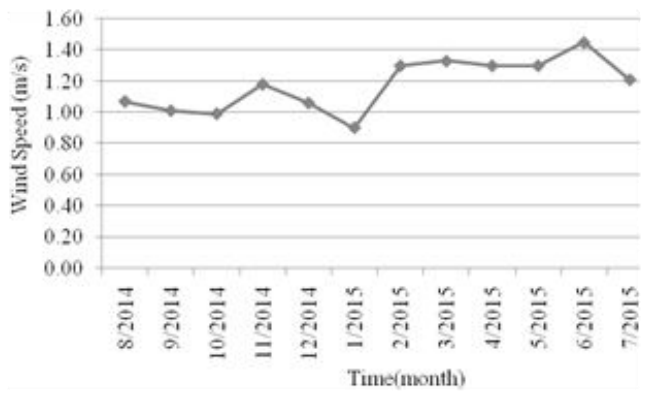

Figure 14. Wind speed variation in the environment

\section{B. Corrosion of Mild Steel as a Function of Time}

For Type A, Type B, and Type C steel, twelve specimens of steel for each type are exposed at the same time starting from August, 2014 and after the completion of every month, one plate of each type is removed, cleaned, and weighted, which gives the progressive weight loss of that particular time interval. The exposure time for mild steels is one year. Figure 15 shows the variation of the mass loss of Type A, Type B, and Type $\mathrm{C}$ steels with natural exposure time at study area.

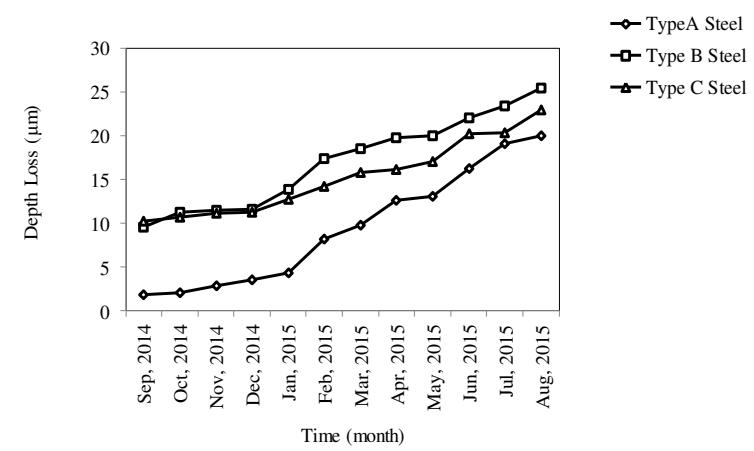

Figure 15. Corrosion depth loss of Type A, B, and C steels vs exposure time

The corrosion rate increases only a little from the beginning to about 4 months (up to December, 2014). At this stage, Type A steel has the least corrosion depth loss, and it is less than nearly half of Type B, and Type C steel. In this period, the time of wetness is high and there 
has little rainfall. Although time of wetness is the main contributor to corrosion, the some incompact corrosion products are washed away by rainfall in this initial stage.

The next four months exposure (from January to April 2015) covers the period of lowest rainfall. In this period, the corrosion losses for Type A and Type B steel are sharply increased and a more than double increase in the corrosion loss, which reach a value of $12.5 \mu \mathrm{m}$ and $20 \mu \mathrm{m}$ for Type A and Type B, respectively, and that for Type $\mathrm{C}$ steel is gradually increased. Due to increase in temperature, it can accelerate the electrochemical reaction of corrosion. In Type $\mathrm{C}$ steel, its chemical contains corrosion resistance alloy (copper), and its corrosion rate is not so high.

The final period (12 months exposure), the highest rainfall (maximum of $571 \mathrm{~mm}$ ), is leading to an increased leaching of the soluble products and deposited salts, and enhancement in the runoff process. Moreover, it also has prolonged time of wetness. These can increase in corrosion rate and the corrosion losses for all types of steel are not different so much.

\section{Analysis and Morphology of the Corrosion Products}

The visual evaluation of the selected steel surface shows that brown corrosion products adhere to the steel surface during exposure to the test conditions. After four months of exposure, three types of steel exhibit a surface with corrosion products as shown in Figure 16, which are identified as flowery structure $\gamma$-FeOOH (Lepidocrocite) for type A steel and cotton balls structure $\alpha-\mathrm{FeOOH}$ (Goethite) for type B and type C steel.

According to literature, in mildly acidic solution, $\gamma$ $\mathrm{FeOOH}$ (the primary crystalline corrosion products) is transformed in to $\alpha-\mathrm{FeOOH}$ in a process that is dependent on the sulfphate concentration and the temperature.

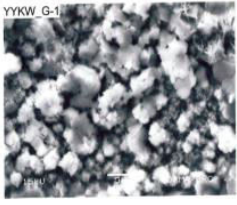

(a)

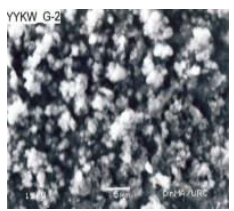

(b)

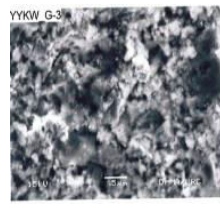

(c)
Figure 16. Morphology of the corrosion products on steel after four month exposure: SEM image (a) type A steel (b) type $\mathrm{B}$ steel (c) type $\mathrm{C}$ steel vs exposure Time

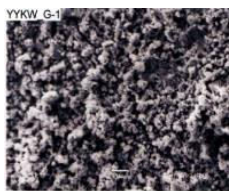

(a)

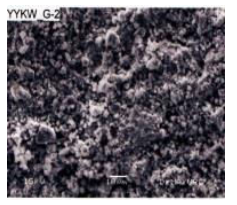

(b)

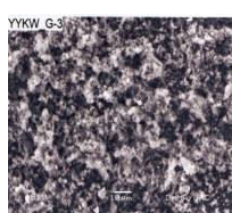

(c)
Figure 17. Morphology of the corrosion products on steel after eight month exposure: SEM image (a) type A steel (b) type B steel (c) type C steel vs exposure Time

After eight months of exposure, a surface with corrosion products as shown in Figure 17, which are identified as cotton balls structure $\alpha$-FeOOH (Goethite) for all types of steel.
After twelve months of exposure, a surface with corrosion products as shown in Figure 18, which are identified as Akaganeite $\beta-\mathrm{FeOOH}($ Cigar-Shaped Crystal) for type A and type B steel due to higher chloride concentration. Type $\mathrm{C}$ steel transformed from $\gamma$-FeOOH to $\alpha-\mathrm{FeOOH}$ and this may be due to decrease in temperature.

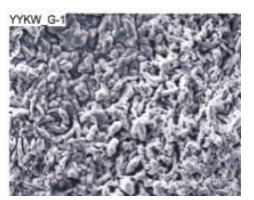

(a)

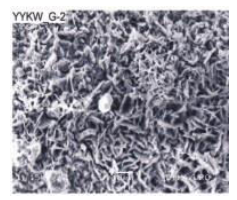

(b)

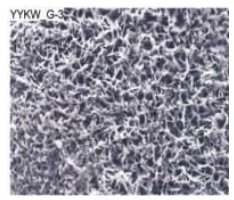

(c)
Figure 18. Morphology of the corrosion products on steel after twelve month exposure: SEM image (a) type A steel (b) type B steel (c) type C steel vs exposure Time

\section{Modeling of Atmospheric Corrosion of Structural} Steels

Firstly, checking for distribution was made. For ratio of cases to independent variables, the following rule of thumb takes into account:

$$
\mathrm{N} \geq\left(\frac{8}{\mathrm{f}^{2}}\right)+(\mathrm{m}-1)
$$

In which $\mathrm{N}$ is the required sample size, $\mathrm{m}$ is the number of independent variables and $\mathrm{f}^{2}=0.02,0.15$, and 0.35 for small, medium, and large effects, respectively.

In this study, at most six of the independent variables would be used in the model. If it is assumed to be 0.15 , then $\mathrm{N} \geq 57$ and thus the available sample size is large enough to at least observe large and medium effects.

For each types of variable, the distribution is check for outliers. The present of outliers is detected with standard scores in excess of 3.29 ( $\rho<0.001$, two tailed test) standard deviations below or above the mean. No outlier is present.

The following observations are used for the dependent and independent variables:
(i) depth of corrosion
:Corros
(ii) time of wetness (hours)
: TOW
(iii) average daily wind speed $(\mathrm{m} / \mathrm{s}) \quad$ : WS
(iv) average daily rainfall $(\mathrm{mm}) \quad: \mathrm{RF}$
(v) temperature $\left({ }^{\circ} \mathrm{C}\right)$
(vi) relative humidity (\%)
: T
: RH

The stepwise multiple regression analysis of the data is carried out in order to obtain the best regression model. The statistical analysis is performed with SPSS statistical software packages.

The initial models are considered with multiple linear regression method including all variables (TOW, WS, $\mathrm{RF}, \mathrm{T}$ and $\mathrm{RH})$. Coefficient of determination, $\mathrm{R}^{2}$ and level of significant, $\alpha(0.05)$ are used to check the best fit for the models. After checking, the best fit models obtained for three types of steel are shown in Table 2.

The variables showing a significant contribution to the model is time of wetness for all types of steel. Other variables may be excluded since their effects could be included by the selected ones.

Table 3. Corrosion models for three types of steel 


\begin{tabular}{lcl}
\hline Type & Description & $\mathrm{R}^{2}$ \\
\hline Type A & Corros $=-3.069+0.005$ TOW & 0.943 \\
Type B & Corros $=5.768+0.007$ TOW $-0.007 R F$ & 0.986 \\
Type C & Corros $=7.203+0.003$ TOW & 0.979 \\
\hline
\end{tabular}

According to final models, for all types of steel, time of wetness is the main contributor and for type B steel, negative effect of rainfall can be seen.

\section{E. Prediction of Atmospheric Corrosion of Structural Steels}

After modeling, prediction of atmospheric corrosion of structural steels is done based on Linear Bi-logarithmic Law.

$$
\mathrm{C}=\mathrm{At}^{\mathrm{b}}
$$

In which $\mathrm{C}$ is the loss of weight due to corrosion and $\mathrm{t}$ is the exposure time. The initial corrosion loss observed during the first unit time of exposure is described by A, while $b$ is a measure of the long term decrease in corrosion rate or passivity of materials which is directly dependent on the metal, the physical-chemical atmospheric conditions and the exposure conditions. A and $b$ values are calculated based on ASTM G 101 .

The mass loss obtained for the samples are converted to corrosion loss (in $\mu \mathrm{m}$ ) so as to get a clearer view of the corrosion damage on metals. The results of corrosion loss against the exposure time are shown in Figure. 15.

The plots of log corrosion data vs. log exposure time are linear. Thus, it is reasonable to accept the verification of the law of power function (Equation 2). The equation of the trend curve, for each type of steel, and the respective coefficient of determination $\left(R^{2}\right.$ value $)$ are shown in Table 4.

Table 4. Equation of trend curve for corrosion of structural steels

\begin{tabular}{lll}
\hline Type of samples & $\begin{array}{c}\text { Equation of } \\
\text { trend curve }\end{array}$ & $\mathrm{R}^{2}$ value \\
\hline $\mathrm{A}$ & $C=1.28 t^{0.98}$ & 0.961 \\
$\mathrm{~B}$ & $C=8.54 t^{0.36}$ & 0.927 \\
$\mathrm{C}$ & $C=9.25 t^{0.24}$ & 0.821 \\
\hline
\end{tabular}

From the obtained high $\mathrm{R}^{2}$ value, it can be accepted that Equation 2 represents well the corrosion behavior of structural steels in Yangon. For Type B steel samples, the $b$ value is near to 0.5 , which suggest that the current's film is protective and inhibits further corrosion by diffusion.

For Type A steel samples, the b value is 0.98 , which is very high and suggests that the rust layer was loosely adherent, which resulted in an increase in the corrosion reaction. For Type $\mathrm{C}$ steel samples, in contrast, the $\mathrm{b}$ value is 0.24 , which result from a decrease in the diffusion coefficient with time through recrystallisation, agglomeration, compaction, etc. of the rust layer.

\section{CONCLUSION}

1. After one year of exposure, a surface with corrosion products, which are identified as Akaganeite $\beta$ $\mathrm{FeOOH}$ (Cigar-Shaped Crystal) for type A and type $\mathrm{B}$ steel. Type $\mathrm{C}$ steel transformed from $\gamma$-FeOOH to $\alpha-\mathrm{FeOOH}$ and this may be due to decrease in temperature.

2. From modeling of corrosion, TOW is the main influence factor that causes deterioration.

3. For long term prediction, type $\mathrm{C}$ steel is the best due to the present of $\mathrm{Cu}$, which can resist the corrosion rate to some extent.

\section{AKNOWLEDGEMENT}

The author would like to offer special thanks to research group of "KUSPIRITS: Corrosion and Deterioration of Construction Materials and Strategic Maintenance of Infrastructures on Southeast Asia" for their kindly helping throughout for research program. Special thanks are also offer to Department of Engineering Chemistry, Yangon Technological University for helping in cleaning procedure for removal of corrosion products from steel samples. The author would like to thank all the persons who have helped towards the successful completion of this paper.

\section{REFERENCES}

[1] Roberge PR, Handbook of Corrosion Engineering. The McGraw-Hill Companies, Inc; New York 2000.

[2] Hays, G.F.(2010)Now is the Time. World Corrosion Organization.

[3] N. B. S. Publication, Economic Effects of Metallic Corrosion in the United States, Publication No. 511, National Bureau of Standard, Washington, DC (1987)

[4] Katsuhiko Asami and Michio Kikuchi, "Characteristics of Rust layers in weathering steels: Air-exposed for a long period" Institute of Material Research, Tohoku University, Sendai 9808577, Japan

[5] corrosion-doctors.org/AtmCorros/iso9223.htm

[6] Bringas, J.E. Editor, 2004. Handbook of Comparative World Steel Standards, Third Edition. ASTM International Standards Worldwide

[7] ISO 9226: Corrosion of metals and alloys-corrosivity of atmospheres - determination of corrosion rate of standard specimens for the evaluation of corrosivity

[8] ASTM G 101-04: Standard guide for estimating the atmospheric corrosion resistance of low-alloy steel.

[9] nInternational Standard Organization -ISO 8407: Corrosion of Metals and Alloys-Removal of Corrosion Products from Corrosion Test Specimens

[10] Japan Infrastructure Partners (JIP), September 2012. Current Saturation and Issues of Myanmar's Bridge Work

[11] Japan International Cooperation Agency, September 2012. Research Study on Review and Application of the Bridge Engineering Training Center Project in Myanmar. Final Report

[12] International Standard Organization-ISO 8565: metals and alloys-Atmospheric corrosion testing-General requirements 